\title{
A U tilização da Simulação Dinâmica como Ferramenta de Apoio à Gestão de Bacias Hidrográficas: O Caso do Arroio Dilúvio em Porto Alegre, RS
}

\author{
O thon Fialho de Oliveira \\ Agência Nacional deÁguas \\ othon.oliveira@ana.gov.br \\ Carlos André Bulhões M endes, Francisco Carlos Bragança de Souza \\ Institu to de Pesquisas H idráulicas - UFRGS \\ mende@@iph.ufrgs.br, braganca@iph.ufrgs.br
}

Recebido: 10/07/07 - revisado: 17/03/08 - aceito: 24/11/10

RESUM 0

A utilização de modelos hidrológicos para entender o comportamento do ciclo da água numa bacia hidrográfica é uma prática corrente nas atividades de planejamento do a proveitamento dos recursos hídricos. No entanto, nem sempre tem sido fácil utilizar estes modelos no processo de tomada de decisão. Isto se deve mu ito ao fato de qu e para utilizar estes modelos é necessário que os decisores possuam um conhecimento específico sobre os parâmetros que foram modelados. Além disso, a quantidade de elementos que são necessários para descrever o comportamento hidrológico pode dificultar bastante 0 enten dimento do sistema como um todo. Para superar esta dificuldade, é proposta a utilização de modelos de simulação dinâmica baseados nos fun damentos da área de estudos conhecida como "dinâmica de sistemas", cujo objetivo é estudar sistemas complexos considerando todos seus elementos constituintes simultan eamente. Estes modelos são construídos para facilitar a avaliação de um sistema complexo por meio da análise da influência de cada elemen to que o integra sobre os demais e sobre 0 todo. Consideran do-sea bacia hidrográfica como o sistema a ser estudado, foi criado um modelo de simulação dinâmica para apoiar o processo decisório de um caso prático, o Programa Pró-Dilúvio da Prefeitura de Porto Alegre (RS), o qual visa promover ações que conduzam à mehoria da qualidade das águas da Bacia do Arroio Dilúvio através da ação conjunta de diversos órgãos municipais. En tre as dificuldades enfrentadas estão a identificação das áreas críticas da bacia a serem atendidas prioritariamente e a avaliação da possível repercussão em longo prazo das ações no combate à poluição gerada pelo lançamento de efluentes domiciliares e em relação à poluição difusa oriunda das águas pluviais. Entre outras coisas, foi observado que a utilização de modelos de simulação dinâmica permite um maior conhecimen to do problema pelos decisores e quea aplicação destes modelos em grupos pode ser bastante útil para facilitar que a negociação da alternativa a ser adotada atinja uma solução de consenso. A pesar destes resultados positivos, verificou-se também que as simplificações realizadas du rante a concepção destes modelos podem gerar desconfiança nos u suários ou mesmo in duzir a tomada equivocada de decisão.

Palavras-chave: gestão de bacias; simula ção dinâmica; solu uções de consenso; poluição pon tual e difu sa.

INTRODUÇÃO

Um dos grandes empecilhos à gestão das águas diz respeito à dificuldade do gestor de definir os pontos críticos a serem atendidos prioritariamente. Isto acontece, em grande parte, devido à dificuldade de filtrar as informações existentes para se obter parâmetros que permitam analisar de maneira eficaz a situação. Neste sentido, é necessário que tanto as informações sejam consistentes, quanto tenham utilidade prática para os tomadores de decisão, ou seja, não sirvam apenas para compor um banco de dados.

Como se parte do princípio que a informação deve ser útil para o gestor, então nada mais natural que sua identificação seja feita abordando-se todos os aspectos considerados como relevantes pelos mesmos. Dessa forma, a realização de entrevistas ou a elaboração de questionários que procurem identificar estes aspectos é fundamental. Neste trabalho, optou-se por identificar estas informações através de entrevistas. Além disso, para que fosse 
possível estabelecer uma regra de identificação destes parâmetros, utilizaram-se os conceitos de indicadores e modelo PSR (Pressão-Situação-Resposta).

Além da dificuldade de se identificar estes aspectos a serem considerados dentro do modelo de suporte à decisão, existe a dificuldade prática concernente a sua própria utilização. Sabe-se que existe uma distância muito grande entre o que é desenvolvido pelos estudiosos e o que é feito por quem trabaIha apenas no meio prático. Dentre as dificuldades identificadas, pode-se citar a falta de intimidade dos tomadores de decisão com relação aos novos modelos. Os decisores, por não entenderem os mecanismos por detrás de um determinado modelo, acabam desconfiando de seus resultados e optando por técnicas mais simples que dominam. Às vezes, até mesmo a própria complexidade dos modelos os torna inadequados para usuários pouco experientes e que desejam apenas obter uma estimativa preliminar. Além disso, a grande quantidade de parâmetros normalmente requeridos para executar alguns modelos os torna pouco atraentes.

Neste trabalho, propõe-se o desenvolvimento de um modelo simplificado para representar os processos físicos envolvidos com a geração de poluição na bacia hidrográfica do Arroio Dilúvio, em Porto Alegre (RS), com a finalidade de auxiliar os gestores a simularem diferentes políticas e ações. 0 modelo foi desenvolvido junto ao Programa PróDilúvio da Prefeitura de Porto Alegre, o qual é encarregado de propor ações que conduzam à melhoria da qualidade das águas do Arroio Dilúvio através da ação conjunta de diversos órgãos municipais.

A identificação dos indicadores que representam o problema foi feita a partir de entrevistas realizadas com membros do programa. Depois de construído, o modelo foi testado e avaliado numa sessão especial, onde participaram tanto os membros do Programa quanto outros técnicos das instituições integrantes. As alternativas simuladas foram construídas durante a sessão e, ao final, os participantes receberam um questionário de avaliação.

\section{MATERIAISE MÉTODOS}

Nesta seção, são descritos sumariamente a área de estudo, o processo de obtenção dos indicadores, a construção das relações entre as variáveis e a formulação do modelo de simulação dinâmica.
Área de Estudo

Com uma área total de $77,9 \mathrm{~km}^{2}$ distribuídas entre os municípios de Viamão e Porto Alegre, a Bacia do Arroio Dilúvio possui uma população estimada em 523 mil habitantes em 2006. Próximo às cabeceiras, na divisa dos municípios, o Dilúvio se une a alguns arroios para formar a Represa da Lomba do Sabão, onde são captados cerca de 3,6\% da água bruta destinada aos consumidores de Porto Alegre. Ao longo do Dilúvio existe também uma das principais avenidas de Porto Alegre, a Ipiranga, a qual serve como eixo de integração subúrbio-centro das atividades socioeconômicas. A figura 1 situa a Bacia do Dilúvio nos municípios de Porto Alegre e Viamão.

Apesar da importância do Dilúvio, a população que convive ou circula na área sofre constantemente com a poluição, o mau aspecto das águas e os odores desagradáveis. Grande parte da poluição gerada no Arroio é proveniente do lançamento irregular de esgotos domiciliares na rede pluvial. Há também a poluição gerada pela lavagem dos poluentes acumulados na superfície do solo pela ação da chuva. De Luca et al. (1990) avaliaram as águas das chuvas e da drenagem superficial na Região Metropolitana de Porto Alegre e alertaram para o fato de que a poluição gerada pela lavagem da superfície do solo pode ser tão grave quanto a poluição de fontes pontuais.

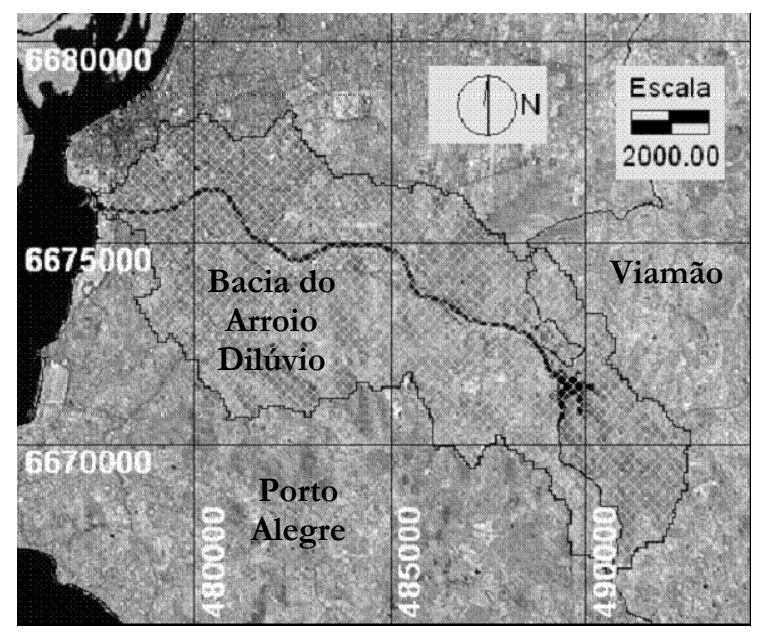

Figura 1 - Localização da Bacia do Arroio Dilúvio.

Utilizando-se os dados do censo de 2000 do Instituto Brasileiro de Geografia e Estatística (IBGE, 2000) referente aos 818 setores censitários compreendidos entre Viamão e Porto Alegre que fazem 
parte da Bacia do Arroio Dilúvio, observa-se que cerca de $51 \%$ da população é atendida por esgotamento sanitário, $97 \%$ por coleta de lixo e $94 \%$ por abastecimento d'água. Em relação às redes de esgotos, os dados mostram também que a situação é mais precária em Viamão, na cabeceira da Bacia.

Para solucionar o problema da poluição na Bacia, a Prefeitura de Porto Alegre lançou, em 2005, o Programa Pró-Dilúvio. O programa conta com a participação de diversos órgãos municipais e se propõe, entre outras coisas, a executar ações de monitoramento, de levantamento das principais fontes de poluição, de fiscalização, de licenciamento ambiental, de manutenção das redes de esgoto e pluvial e de educação ambiental.

\section{Indicadores}

A discussão se o desenvolvimento da sociedade é sustentável do ponto de vista econômico, ambiental e social fez com que muitos países avançassem nas políticas de prevenção. Com isso, aumentou também o interesse em avaliar o nível de eficiência na implementação das políticas e se estas satisfazem os objetivos pré-estabelecidos, o que têm motivado o desenvolvimento de indicadores como uma ferramenta de suporte à decisão e de avaliação do desempenho das políticas (Organization for Economic Co-operation and Development - OECD, 2001). A OECD (2003) definiu alguns critérios a serem considerados na definição dos indicadores apropriados para representar um contexto decisório, entre os quais se destacam:

- Relevância e utilidade para os usuários: o indicador deve dar uma visão representativa das condições ambientais, pressões sobre 0 ambiente ou respostas da sociedade; deve ser simples, sensível a mudanças e hábil para mostrar tendências; deve fornecer uma base para comparações; e, deve ter um valor limite ou de referência;

- Profundidade analítica: o indicador deve estar teoricamente bem fundamentado em termos técnicos e científicos; deve estar baseado em padrões gerais e num consenso geral; e, deve se prestar a elos com modelos econômicos, previsões e sistemas de informação;

- Mensurabilidade: os dados necessários para caracterizar o indicador devem ser adquiridos numa razoável relação custo/ benefício que viabilize sua atualização regular. Estes dados também devem estar bem documentados e devem possuir uma qualidade confiável.

Para auxiliar no procedimento de escolha dos indicadores, a OECD desenvolveu modelos baseados nas relações de causa e efeito existentes entre as ações humanas e suas repercussões no meio. Estes modelos apresentam uma estrutura básica similar, representada no modelo PSR - Pressão/ Situação/ Resposta ( ).

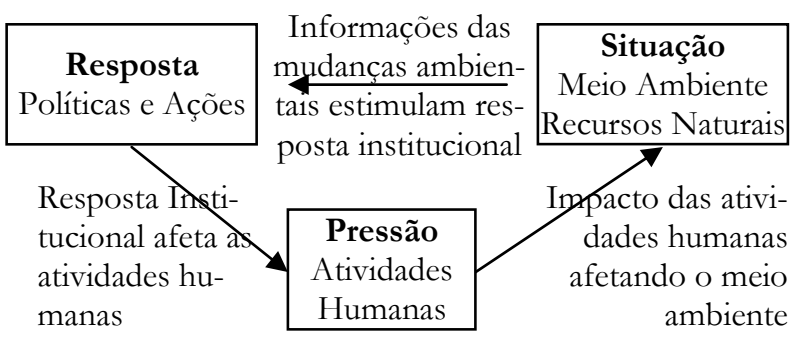

Figura 2 - Representação típica do modelo PSR (Fonte: FAO , 2006).

Os indicadores associados à Pressão se referem normalmente às atividades humanas (indústria, agricultura, etc), enquanto que os indicadores de Situação refletem as condições ambientais (atmosfera, água, solo, recursos naturais, saúde humana, bem-estar, etc) e os indicadores de Resposta se relacionam aos instrumentos usados para gerenciar o meio ambiente, tais como taxas sobre a utilização do recurso natural.

Os Indicadores também podem ser agrupados na forma de índices. Como exemplo, pode-se citar o índice de desenvolvimento humano (IDH), que é bastante usado para avaliar as políticas sociais, ou o Produto Interno Bruto, que é utilizado para avaliar a riqueza de um país. Além disso, decisores e técnicos trabalham com informações em diferentes escalas, enquanto aqueles trabalham com informações reduzidas para poder definir claramente 0 rumo das ações, os técnicos necessitam de informações bem precisas para elaborar projetos.

Neste trabalho, os indicadores foram identificados a partir de entrevistas realizadas com membros do grupo Pró-Dilúvio. Após colher as informações, os dados foram organizados e interpretados de acordo com o modelo PSR. 


\section{Dinâmica de Sistemas}

A Dinâmica de Sistemas teve início no final da década de 50 através dos estudos de Jay Forrester sobre processos industriais no MIT (Massachusetts Institute of Technology) e é um método para estudar o mundo ao nosso redor. Ao contrário de alguns pesquisadores que estudam apenas uma parte do sistema, os pesquisadores desta área do conhecimento analisam as coisas como um todo. O conceito central na dinâmica do sistema é entender como todos os objetos em um sistema interagem entre si (MIT SDEP, 2010).

Ao se encarar um objeto em estudo como um sistema é possível estabelecer diversas relações entre seus elementos. Através destas relações, uma simples variável pode afetar outras variáveis no tempo, as quais podem voltar a afetar a variável original, e assim por diante. 0 conjunto de relações entre estes elementos constituirá o modelo de comportamento do sistema. A dificuldade de se avaliar sistemas complexos faz com que pesquisadores tendam a discretizar o objeto e analisar suas partes. Com o intuito de avaliar o todo simultaneamente, constróise um modelo de simulação dinâmica a partir das relações entre os elementos do sistema.

Os modelos de simulação dinâmica têm ganhado popularidade nos últimos anos e, em conseqüência disto, alguns pacotes computacionais foram desenvolvidos para auxiliar na elaboração dos modelos. Rizzo et al. (2006) avaliaram o balanço de energia de uma superfície úmida através dos softwares de simulação dinâmica STELLA 5.0, MADO NNA 7.0.2, GOLDSIM 7.51.100 e SIMULINK 4.1.2.4 e verificaram que os modelos se ajustam bem ao cálculo pretendido, mas variavam de acordo com a capacidade computacional e com a facilidade de manuseio.

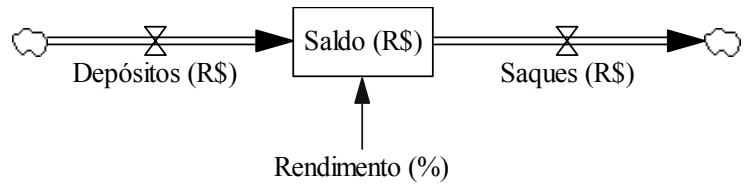

Figura 3 - Exemplo ilustrando uma estrutura bastante usada nos modelos de simulação dinâmica.

Vários dos pacotes computacionais adotam uma representação semelhante das variáveis do modelo de simulação dinâmica. Basicamente estas variáveis se distinguem em três grupos: estoque ("Ievel"), que representa um acúmulo; taxa ("rate"), que representa a taxa de fluxo que altera o estoque; e, auxiliares. A figura 3 ilustra um caso bem elementar do saldo de uma conta poupança, onde o saldo é a variável de estoque, as diferenças entre os saques e os depósitos representam a taxa de acúmulo e a variável auxiliar é a taxa de rendimento que incide sobre o saldo. De uma maneira geral, esta representação pode ser bastante útil para fornecer uma visão global das relações dos componentes do sistema, pois, uniformiza a representação gráfica.

Independente da maneira como se representam e se manipulam os objetos constituintes do modelo, é fundamental destacar que o usuário deve ter facilidade em interpretar o modelo e fazer simulações, de forma a favorecer a utilização do mesmo como ferramenta de suporte à decisão. Desta forma, a concepção de um modelo por meio de programação computacional pode até ser mais recomendada, pois permite que o desenvolvedor utilize sua capacidade criativa para elaborar um modelo que se ajuste melhor aos propósitos.

Escolhida a forma como será desenvolvido o modelo de simulação dinâmica, parte-se para a concepção propriamente dita. Stave (2003) cita os passos básicos para análise de um sistema dinâmico:

1. Definição do problema: onde são observados os aspectos-chave que serão modelados;

2. Descrição do sistema: engloba a identificação da estrutura causal entre os elementos constituintes do sistema;

3. Desenvolvimento do modelo: é a representação gráfica da dinâmica da estrutura;

4. Validação do modelo: é a aplicação em cenários de referência para verificar a consistência e a influência das considerações simplificadoras;

5. Uso do modelo para análise de políticas e ações: uma vez validado, o modelo pode ser usado para verificar as ações ou políticas de governo;

6. U so do modelo para comunicação: é a utilização do modelo para conscientizar a população sobre o impacto das políticas e ações.

Os dois primeiros itens se referem à preocupação com o reconhecimento do problema e a descrição do sistema, a partir da identificação dos elementos essenciais a serem considerados no modelo e do entendimento da relação existente entre eles. Os dois seguintes tratam da construção e validação do modelo, enquanto os dois últimos são a aplicação do modelo como ferramenta de suporte à decisão e conscientização pública. 


\section{RESULTADOS}

Nesta seção são apresentados os critérios de avaliação das alternativas e o modelo PSR gerado como resultado das entrevistas e o modelo de simulação dinâmica elaborado para auxiliar o processo de decisão.

\section{Critérios de avaliação e Modelo PSR}

Os critérios de avaliação do modelo foram estabelecidos a partir da interpretação, segundo os conceitos do Modelo PSR, das informações de duas entrevistas realizadas com integrantes do grupo PróDilúvio, a coordenadora do programa e funcionária da Secretaria Municipal de Meio Ambiente (SM AM) e uma representante do Departamento Municipal de Água e Esgotos (DMAE). Os critérios para representação do modelo são descritos a seguir:

TEM A: Aspecto técnico-ambiental.

Poluição Difusa

Pressão: Deposição de lixos e outros poluentes na superfície do solo;

Situação: Chuvas arrastam os poluentes e contaminam o corpo receptor (aumento das concentrações e cargas de poluentes);

Resposta: Controle das fontes com medidas não estruturais (áreas verdes, coleta e disposição correta do lixo, educação, etc) e estruturais (bacias de detenção, pavimento poroso, etc).

Poluição Pontual

Pressão: Lançamento de poluentes diretamente no corpo receptor;

Situação: Contaminação direta do corpo receptor (aumento das concentrações e cargas de poluentes); Resposta: Identificação, fiscalização e correção das fontes de poluição.

Indicador: índice de qualidade da água

TEM A: Aspecto político-institucional

Recursos financeiros

Pressão: Falta de investimento;

Situação: Processos de degradação continuam a aumentar (problemas com ligações irregulares, rede de esgotamento, etc);

Resposta: Obter mais recursos (Fundo Municipal, participação de empresas, captação externa e outras fontes).

Fragilidade insti tucional

Pressão: Falta de coordenação política;

Situaçãa: Ações de intervenção ineficientes (morosidade, aumento dos custos, etc);
Resposta: Pressão na classe política, mudança da estrutura institucional, etc.

Indicador: percentual da população sem redes de esgotamento sanitário ou pluvial

TEMA: Aspecto político-social

Ocupação do solo

Pressão: Crescimento populacional desordenado;

Situação: Aumento do escoamento superficial, com aumento das cargas poluidoras;

Resposta: Definição de limites máximos de ocupação. U so do solo

Pressão: Mudança da cobertura natural do solo;

Situação: Aumento do escoamento superficial e mudança dos tipos de poluentes;

Resposta: Controle e zoneamento urbano.

Indicador: relação entre a densidade habitacional real e a recomendada pelo Plano Diretor de Porto Alegre

Os critérios de avaliação podem também ser apresentados sinteticamente na forma de uma árvore de hierarquia dos critérios (Figura 4). A vantagem básica desta representação é a imediata visualização dos critérios.

\section{Modelo de Simulação Dinâmica}

Antes de tudo é importante lembrar que o modelo não é o objetivo deste trabalho, mas apenas um meio, e por esta razão a representação dos elementos deve estar ajustada com a finalidade pretendida. 0 objetivo principal é dar suporte aos decisores através da melhoria da compreensão que os mesmos têm sobre o contexto decisório. Isto não significa dizer que serão negligenciados aspectos relevantes, mas que apenas o mais importante é a compreensão do funcionamento integrado do sistema e da ordem de grandeza relativa das variáveis para que se possa indicar em que sentido devem ser as medidas a serem tomadas para mitigar o problema.

Para atender ao que se propõe, o modelo de simulação deste trabalho deve contemplar os critérios definidos anteriormente, deve permitir que 0 meio físico seja caracterizado adequadamente e deve ter uma interface amigável que permita realizar alterações dos parâmetros durante a simulação. Além disso, é interessante que os diversos cenários de alternativas simulados recebam uma pontuação de acordo com os critérios estabelecidos, para facilitar as comparações de cenários. 
A Utilização da Simulação Dinâmica como Ferramenta de Apoio à Gestão de Bacias Hidrográficas: O Caso do Arroio Dilúvio em Porto Alegre, RS

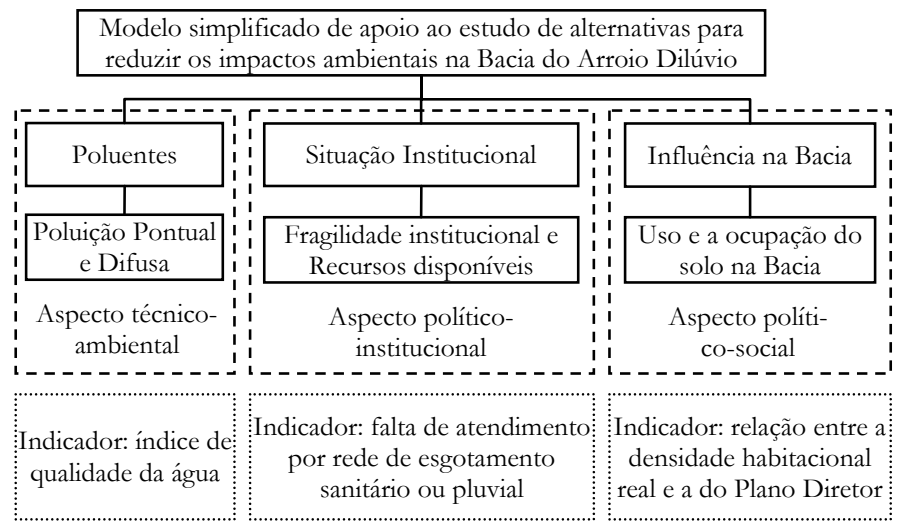

Figura 4 - H ierarquia dos critérios de avaliação.

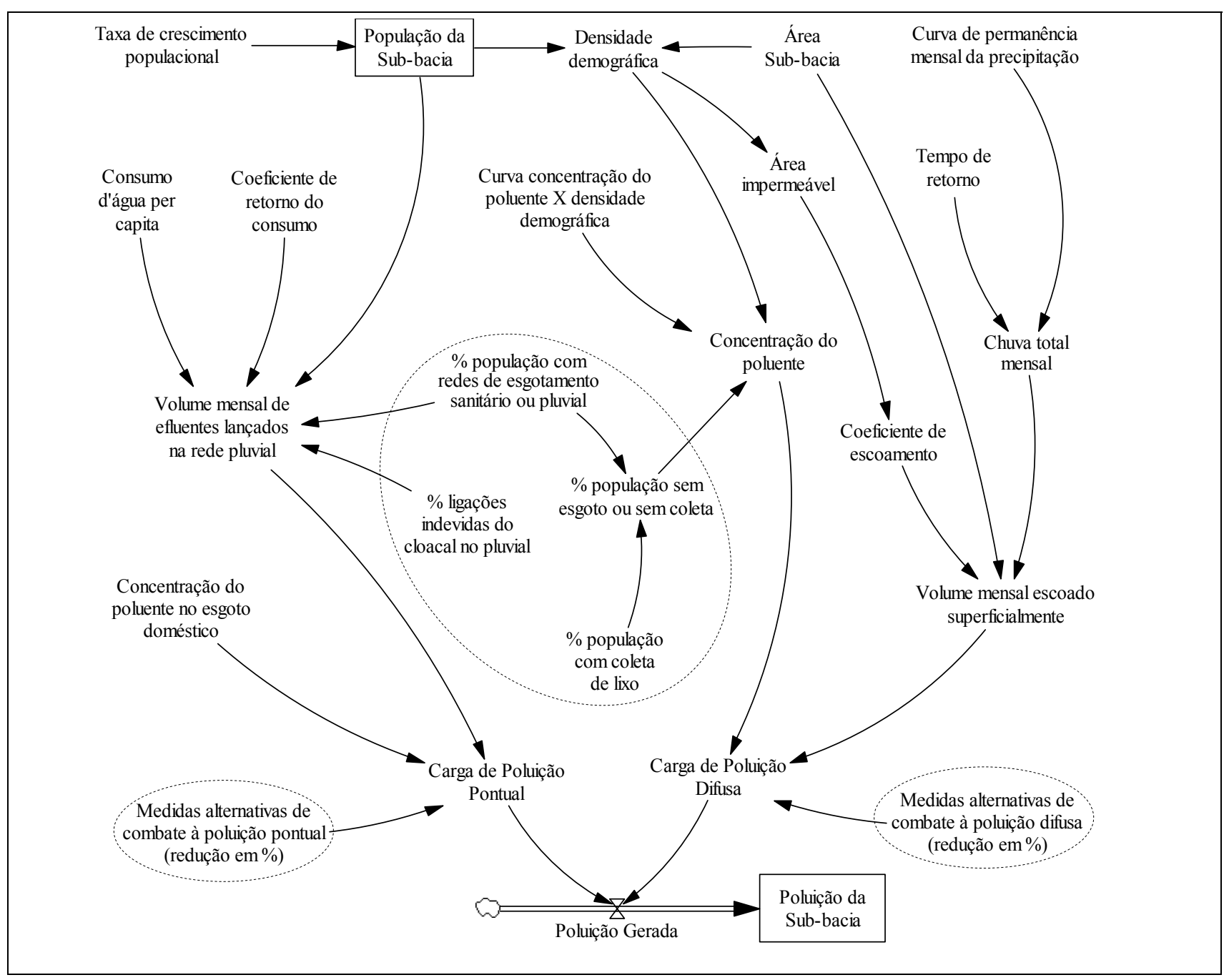

Figura 5 - Representação esquemática do processo físico. 
Desta forma, o modelo de simulação dinâmica é composto por dois módulos básicos:

1. Representação física do processo: é a descrição das principais variáveis envolvidas no processo de poluição da Bacia do Dilúvio e da relação de causa e efeito existente entre elas. É útil para ajudar o decisor a entender como funciona o mecanismo de poluição na Bacia e a repercussão de suas decisões.

2. Avaliação das alternativas: é quando o cenário estabelecido para toda a bacia é avaliado de acordo com os critérios estabelecidos e recebe uma pontuação para cada um deles, além de uma nota global. Esta avaliação serve de referência para comparação com outros possíveis cenários.

Além dos dois módulos, o modelo de simulação dinâmica proposto incorpora características de um Sistema de Informações Geográfico (SIG) e de um avaliador de problemas multicritério. 0 componente SIG é devido à apresentação dos dados de forma distribuída no espaço, onde cada uma das 26 sub-bacias do Arroio Dilúvio possui um conjunto de informações que alimentam o módulo de representação física do processo, cujos resultados servem de entrada para o módulo de avaliação das alternativas.

Representação física do processo

Para cada uma das 26 sub-bacias do Arroio Dilúvio foi definido um conjunto de variáveis para representar os principais processos físicos envolvidos na geração e no transporte dos poluentes. 0 estabelecimento das relações entre as variáveis desses processos foi feito assumindo-se como pressuposto básico o fato de que a urbanização agrava os problemas ambientais e interfere nas variáveis que os representam. Segundo Drew (1983) apud Bollmann (2003), virtualmente todos os aspectos do ambiente são alterados pela urbanização. Bollmann (2003) comenta ainda que, regra geral, a intensidade da mudança está ligada à densidade da área edificada e à extensão da ocupação.

Em relação à forma como a poluição ocorre, podem-se considerar dois tipos de fontes: a difusa e a pontual. De uma forma geral, a poluição pontual se refere às cargas lançadas diretamente no meio ambiente ou curso d'água por uma fonte que pode ser facilmente identificada e a poluição difusa corresponde à poluição gerada pela "lavagem" dos poluentes acumulados na superfície do solo durante as chuvas.
Nas cidades, a poluição pontual está ligada normalmente ao despejo irregular de efluentes na rede de drenagem pluvial. A produção per capita de efluentes e a concentração dos diversos poluentes nestas águas podem ser estimados a partir de valores médios apresentados na literatura, destacando-se o consagrado trabalho de Von Sperling (1996).

Em relação à poluição difusa, al guns pesquisadores têm se dedicado a estudar a concentração de poluentes nas águas pluviais em áreas com diferentes graus de urbanização, com destaque ao trabaIho realizado por Bollmann (2003) em Porto Alegre. Através das relações entre a concentração de poluentes e a densidade populacional apresentadas pelo autor, é possível estimar a produção total de cargas difusas em áreas urbanas.

As estimativas de poluição pontual e difusa permitem estabelecer um modelo empírico de geração de poluição. Este modelo deve ser usado com ressalvas e apenas para fins de suporte à decisão, pois fornece apenas um indicativo da realidade, uma vez que simplifica processos bem mais complexos e desconsidera, por exemplo, a alteração das concentrações dos poluentes não-conservativos na contabilização das cargas.

As variáveis utilizadas, bem como a relação entre elas, são mostradas na Figura 5. 0 equacionamento matemático completo do modelo pode ser obtido em Oliveira (2006).

\section{Avaliação das alternativas}

Os dados do processo físico alimentam o módulo de avaliação das alternativas, que é composto pelos critérios (ou "Pontos de Vista Fundamentais"): Poluentes (PVF-1), Situação Institucional (PVF-2) e Influência na Bacia (PVF-3). Estes critérios são medidos através dos seus indicadores, que são o índice de qualidade das águas, a falta de atendimento por rede de esgotamento sanitário ou pluvial e a relação entre a densidade habitacional real e a do Plano Diretor, respectivamente.

Os resultados obtidos nesta etapa seguem uma mesma escala, de acordo com as preferências dos decisores. Nesta escala, há dois níveis de referência: neutro, que recebe o valor " 0 ", e bom, que recebe o valor "100". Os valores abaixo do nível neutro correspondem às alternativas que se encontram abaixo da expectativa (insatisfatórias) e os valores acima do nível bom se referem àquelas que superam as expectativas. Os detal hes sobre o desenvolvimento do método podem ser obtidos em Oliveira (2006). 


\section{Alguns cenários simulados}

Com o objetivo de se construir um modelo de mais fácil compreensão e manipulação e com a possibilidade de apresentar resultados de diferentes maneiras (mapas, tabelas e gráficos), optou-se por desenvolver o modelo de simulação dinâmica por meio de programação computacional, tendo sido utilizado o software Delphi Borland 5.0.

Para ilustrar a utilização do modelo e sua capacidade de gerar aprendizado, são apresentados alguns dos cenários simulados, que representam diferentes políticas de saneamento. Os cenários foram construídos modificando os valores dos seguintes parâmetros presentes na Figura 5: o percentual da população atendida pelo serviço de coleta de lixo; o percentual da população atendida por rede de esgotamento sanitário; o percentual da população que faz ligação indevida do esgoto cloacal no pluvial; e, as medidas alternativas de redução da poluição pontual e difusa. As descrições dos cenários e das alterações em relação à situação atual são descritas a seguir:

- Cenário 01: Ausência de política de saneamento. Neste cenário não haverá alteração do quadro estrutural da bacia. Corresponde, portanto, à pior situação;

- Cenário 02: Política intensa de aumento no atendimento da população por coleta de lixo em 5 anos. Implica no aumento do atendimento do serviço de coleta de lixo linearmente até 0 ano 2011, até alcançar 99,9\% em as todas sub-bacias;

- Cenário 03: Política de ampliação da rede de esgotos existente em 10 anos. I mplica no aumento do atendimento por rede de esgotos linearmente até 0 ano 2016, até alcançar $99,9 \%$ em todas sub-bacias;

- Cenário 04: Política intensa de fiscalização e reparo das ligações indevidas. Implica na redução linear das ligações indevidas em 4 anos (até 0 ano 2010), até alcançar $1 \%$, patamar que será mantido até 0 ano 2026;

- Cenário 05: Política integrada de saneamento em longo prazo (20 anos). Corresponde a um aumento linear no atendimento por rede de esgotos e coleta de lixo entre os anos 2007 e 2026 até alcançar 99,9\% em todas sub-bacias, com implementação de medidas estruturais e não estruturais alternativas, para redução de $5 \%$ da poluição difusa e pontual, e redução linear das ligações indevidas até alcançar $1 \%$ no mesmo período;

- Cenário 06: Política de intervenção localizada. Atua nas sub-bacias responsáveis pela maior carga poluidora. Promove a ampliação da rede de esgotos e a redução das ligações indevidas nas sub-bacias 2, 4, 5, 6, 7, 9 , 10, 11 e 23, esta última com a maior parte em Viamão.

Para exemplificar os resultados, apresentamse os gráficos das concentrações da demanda bioquímica de oxigênio $\left(\mathrm{DBO}_{5 \mathrm{dias}, 20^{\circ} \mathrm{C}}\right)$, medidas em $\mathrm{mg} / \mathrm{l}$. Este parâmetro foi escolhido entre os demais do modelo porque já é bastante utilizado para avaliar a qualidade de um corpo d'água. 0 eixo da abscissa representa o Arroio Dilúvio, de jusante a montante ( figuras 6 a 12) .

De uma forma geral, observa-se um aumento da concentração da DBO ao longo do Dilúvio, caso nenhuma medida seja tomada (Figura 7). Além disso, aumentar o serviço de coleta pode afetar muito pouco na melhoria da qualidade das águas (Figura 8), uma vez que cerca de $97 \%$ da população da bacia já dispõe deste serviço.

Pelo cenário 3 (Figura 9), observa-se que uma política de expansão da rede que não prevê a fiscalização e o controle dos lançamentos irregulares pode ser ineficaz. Da mesma forma, pode ser ineficaz reduzir as ligações irregulares (Figura 10) sem expandir a rede.

Como era de se esperar, uma política integrada de saneamento (Figura 11), atacando todas as causas do problema, é a mais efetiva. Contudo, devese ter em mente que uma solução tão abrangente certamente terá um custo associado bastante elevado em relação às demais, por isso é interessante estudar alternativas que ajam diretamente nos focos mais significativos de geração de poluição. O cenário 6 (Figura 12) ilustra uma configuração intermediária de implementação da política integrada de saneamento, pois atua apenas onde o problema gera efeitos mais graves.

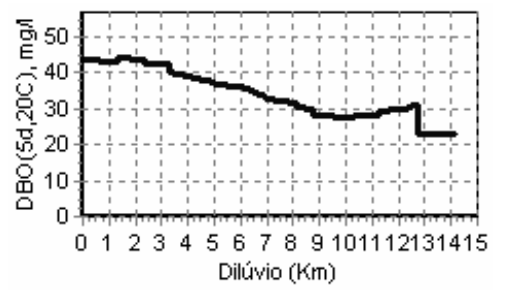

Figura 6 - Estado atual, em maio de 2006. 


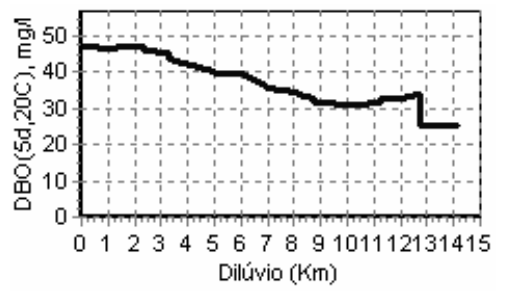

Figura 7 - Cenário 01, em maio de 2026.

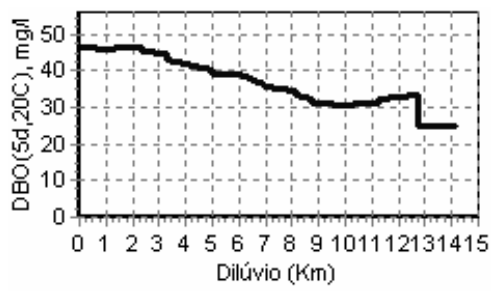

Figura 8 - Cenário 02, em maio de 2026.

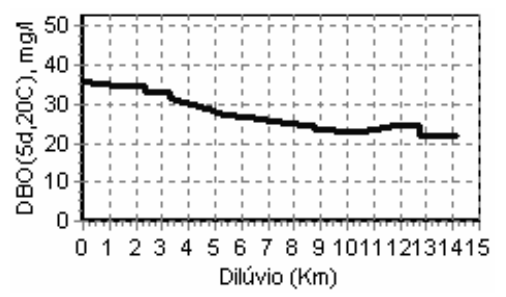

Figura 9 - Cenário 03, em maio de 2026.

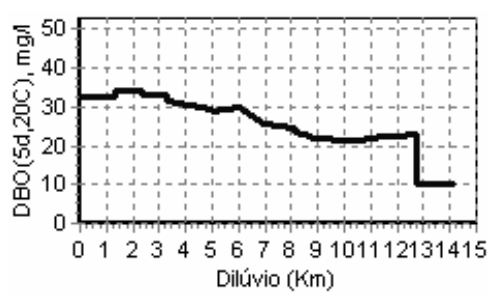

Figura 10 - Cenário 04, em maio de 2026.

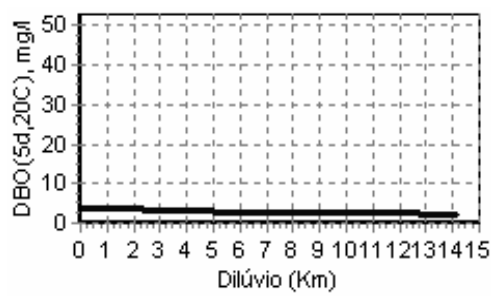

Figura 11 - Cenário 05, em maio de 2026.

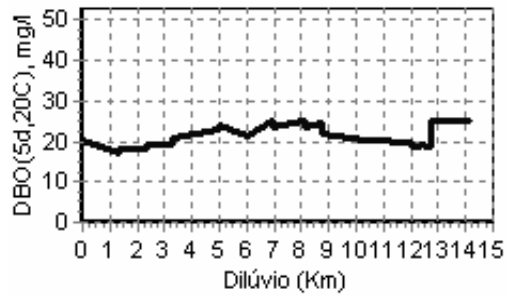

Figura 12 - Cenário 06, em maio de 2026.

Concluído o módulo de representação física do processo, pode-se ter uma idéia da repercussão das diferentes alternativas de gestão. Contudo, a escolha de qual rumo deve ser adotado é um processo mais complexo e depende das preferências dos decisores. Para apoiar esta escolha, são utilizados os dados do módulo de avaliação da alternativa. Convém lembrar que as notas deste módulo se referem a uma média sobre todos os anos, sendo assim, os cenários recebem notas piores nos primeiros anos, 0 que leva o desempenho total para baixo. Assim, para que uma alternativa receba uma nota melhor, é necessário que a mesma contemple ações de curto, médio e longo prazo. Os resultados do módulo de avaliação da alternativa são apresentados na Tabela 1.

Tabela 1 - Avaliação Global e segundo os critérios PVF-1, PVF-2 e PVF-3 dos cenários.

\begin{tabular}{|l|c|c|c|c|}
\hline Cenários & $\begin{array}{c}\text { Nota } \\
\text { Global }\end{array}$ & $\begin{array}{c}\text { PVF-1 } \\
\text { (Poluentes) }\end{array}$ & $\begin{array}{c}\text { PVF-2 } \\
\text { (Situação } \\
\text { Institucional) }\end{array}$ & $\begin{array}{c}\text { PVF-3 } \\
\text { (Influência } \\
\text { na Bacia) }\end{array}$ \\
\hline 01 & $-51,80$ & $-235,14$ & $-10,00$ & 95,31 \\
\hline 02 & $-51,71$ & $-234,87$ & $-10,00$ & 95,31 \\
\hline 03 & $-22,31$ & $-222,09$ & 65,93 & 95,31 \\
\hline 04 & $-51,17$ & $-233,29$ & $-10,00$ & 95,31 \\
\hline 05 & $-25,70$ & $-207,63$ & 40,74 & 95,31 \\
\hline 06 & $-37,46$ & $-223,51$ & 21,48 & 95,31 \\
\hline
\end{tabular}

Como era de se esperar, o cenário 5 é o que obteve o melhor resultado em termos de qualidade das águas, a qual, ainda assim, é considerada insatisfatória (menor que o nível de referência " 0 ").

Sob o critério PVF-2, os cenários 3, 5 e 6 foram os que obtiveram um melhor desempenho, devido a um investimento maior em ampliação das redes de esgoto, o que retrata uma situação políticoinstitucional mais favorável. 0 cenário 3 obteve um desempenho ainda melhor porque os investimentos foram feitos num período de tempo menor. 
Como nenhuma das alternativas contemplou ações que atuariam sobre o uso e ocupação do solo na Bacia, então os valores do PVF-3 foram iguais.

Em relação às notas globais das alternativas, a que apresentou melhor desempenho foi a 3a. Caso os pesos dos critérios sejam alterados, então uma outra alternativa pode obter um desempenho global melhor.

Além de apresentar os resultados em forma de gráficos e tabelas, o modelo apresenta também a distribuição espacial de algumas variáveis analisadas (Figura 13) com o intuito de facilitar a interação dos usuários com a ferramenta computacional, o que contribui para uma redução do tempo gasto na interpretação dos resultados.

U ma discussão mais aprofundada destes resultados e uma explicação detalhada de todas as funcionalidades do modelo de simulação dinâmica construído para este estudo de caso podem ser encontradas em Oliveira (2006).

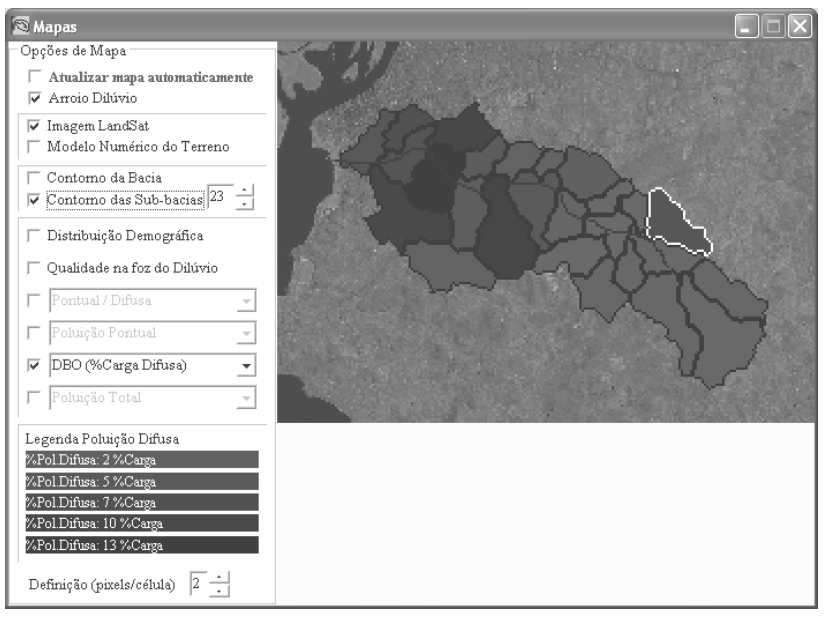

Figura 13 - Representação espacial no modelo.

\section{Avaliação do modelo}

Para saber se o modelo de simulação proposto foi considerado útil aos membros do grupo do Programa Pró-Dilúvio, foi elaborado um questionário. Este questionário foi apresentado ao grupo logo após o modelo ter sido utilizado na elaboração e avaliação das alternativas.

A reunião foi aberta não somente aos funcionários que atuam diretamente no Programa, o que foi muito bom para aumentar a diversidade das respostas, devido às diversas experiências pessoais. Ao todo, 9 pessoas participaram da avaliação.
A seguir, são apresentadas uma síntese das respostas dos nove questionários respondidos:

1) No seu ponto de vista, qual a importância da utilização de modelos de simulação como ferramenta de suporte à decisão?

\begin{tabular}{|c|c|c|c|c|c|c|c|c|c|}
\hline \multirow{2}{*}{ Q uestão 1} & \multicolumn{9}{|c|}{ Avaliadores } \\
\hline & 1 & 2 & 3 & 4 & 5 & 6 & 7 & 8 & 9 \\
\hline Nenhuma & & & & & & & & & \\
\hline Pequena & & & & & & & & & \\
\hline 包 Intermediária & & $x$ & & & & & & & \\
\hline Importante & & & & $x$ & $\mathrm{x}$ & & & $x$ & \\
\hline צrande & $x$ & & $\mathrm{x}$ & & & $x$ & $\mathrm{x}$ & & $x$ \\
\hline
\end{tabular}

2) No seu ponto de vista, qual a importância que o modelo apresentado possui?

\begin{tabular}{|c|c|c|c|c|c|c|c|c|c|}
\hline \multirow{2}{*}{ Q uestão 2} & \multicolumn{9}{|c|}{ Avaliadores } \\
\hline & 1 & 2 & 3 & 4 & 5 & 6 & 7 & 8 & 9 \\
\hline N enhuma & & & & & & & & & \\
\hline Pequena & & & $x$ & & & & & & \\
\hline$\sqrt[n]{\mathbb{n}}$ Intermediária & & $x$ & & $x$ & $x$ & & & & \\
\hline Importante & $x$ & & & & & $\mathrm{x}$ & & $x$ & \\
\hline $\begin{array}{c}y_{\Upsilon 1} \\
\text { Grande }\end{array}$ & & & & & & & $x$ & & $\mathrm{x}$ \\
\hline
\end{tabular}

3) No seu ponto de vista, qual a importância que tem a associação de modelos de simulação com Sistema de Informações Geográfico (SIG) ?

\begin{tabular}{|c|c|c|c|c|c|c|c|c|c|}
\hline \multirow{2}{*}{ Questão 3} & \multicolumn{9}{|c|}{ Avaliadores } \\
\hline & 1 & 2 & 3 & 4 & 5 & 6 & 7 & 8 & 9 \\
\hline Nenhuma & & & & & & & & & \\
\hline $\begin{array}{l}\text { Pequena } \\
\end{array}$ & & & & & & & & & \\
\hline Intermediária & & & & & & & & & \\
\hline Importante & & & & & $x$ & $\mathrm{x}$ & & $x$ & \\
\hline$y \longdiv { \text { Grande } }$ & $x$ & $x$ & $\mathrm{x}$ & $\mathrm{x}$ & & & $\mathrm{x}$ & & $x$ \\
\hline
\end{tabular}

4) No seu ponto de vista, qual a importância que tem a associação de modelos de simulação com modelos multicritério de suporte à decisão?

\begin{tabular}{|c|c|c|c|c|c|c|c|c|c|}
\hline \multirow{2}{*}{ Q uestão 4} & \multicolumn{9}{|c|}{ Avaliadores } \\
\hline & 1 & 2 & 3 & 4 & 5 & 6 & 7 & 8 & 9 \\
\hline Nenhuma & & & & & & & & & \\
\hline Pequena & & $\mathrm{x}$ & & & & & & & \\
\hline$\sqrt[n]{\mathbb{4}}$ Intermediária & & & & & & & & $\mathrm{X}$ & \\
\hline Importante & & & & $\mathrm{x}$ & $\mathrm{x}$ & & & & \\
\hline Grande & $x$ & & $x$ & & & $\mathrm{x}$ & $\mathrm{X}$ & & $x$ \\
\hline
\end{tabular}

5) A simulação dinâmica ajudou a compreender as possíveis alternativas e suas repercussões? 


\begin{tabular}{|l|l|l|l|l|l|l|l|l|l|}
\hline \multirow{2}{*}{ Q uestão 5 } & \multicolumn{9}{|l|}{ Avaliadores } \\
\cline { 2 - 9 } & 1 & 2 & 3 & 4 & 5 & 6 & 7 & 8 & 9 \\
\hline Sim & x & X & & x & x & x & x & x & X \\
\hline Não & & & X & & & & & & \\
\hline
\end{tabular}

De uma forma geral, observa-se que há um consenso entre os avaliadores de que a utilização de modelos de simulação é importante para apoiar o processo de gestão e de que a simulação dinâmica facilita na identificação das alternativas e das suas possíveis repercussões. Além disso, houve uma unanimidade sobre a importância da associação entre modelos de simulação e SIG. Da mesma forma, os avaliadores consideraram importante a associação de modelos de simulação com modelos multicritério de suporte à decisão. Em relação ao modelo apresentado, os avaliadores consideraram a sua importância de intermediária a muito importante.

No questionário também havia um espaço reservado para críticas e sugestões. Questionou-se a confiabilidade dos dados usados no estabelecimento das relações do modelo empírico de geração de poluição e as simplificações no mecanismo de produção e transporte dos poluentes. De positivo, alguns avaliadores comentaram que um modelo como este pode fornecer indicativos que auxiliam no processo de tomada de decisão e que, por ser de fácil visualização, o mesmo pode ser empregado mais facilmente, podendo, inclusive, ter sua utilização imediata, embora o convencimento dos tomadores de decisão deva ocorrer em médio prazo.

\section{DISCUSSÃO DOS RESULTADOS}

A seguir são apresentadas algumas observações importantes sobre a utilização dos modelos de simulação dinâmica para gerar e avaliar alternativas. Dentre os pontos positivos observados, destacam-se:

- A participação dos decisores na identificação dos elementos essenciais a serem representados no modelo de simulação dinâmica e a utilização dos conceitos de indicadores e modelo PSR permitiram estruturar o problema de uma forma mais fiel ao contexto decisório. Além disso, os decisores passam a se identificar mais com o modelo e apoiar sua utilização, sabendo que eles foram fundamentais para sua concepção.
- A implementação de um sistema dinâmico computacional permite a avaliação de várias alternativas de maneira fácil, rápida e clara. Este processo gera aprendizado pelos envolvidos, permitindo a interação dos mesmos sem que necessitem entender profundamente os aspectos técnicos do problema, uma vez que as equações e a formulação teórica já estão embutidas no modelo. Assim, os usuários podem se dedicar mais profundamente ao estudo e geração dos vários cenários de simulação para obter mais conhecimento sobre o problema e entender as repercussões das diversas ações de intervenção.

- A geração de alternativas iterativamente, utilizando o recurso computacional, permite que a solução evolua mais a cada tentativa, convergindo para uma solução satisfatória.

- O modelo de simulação dinâmica pode ser apresentado num grupo de decisores e utilizado como uma ferramenta de negociação para se atingirem soluções de consenso.

- O modelo proposto potencializou a utilização do Sistema de Informação Geográfica como ferramenta de suporte à decisão, uma vez que uniu as informações distribuídas nas sub-bacias com um avaliador de ações.

- A distinção entre as fontes de poluição no modelo torna-se essencial para identificar os principais responsáveis pela poluição, além de permitir entender a repercussão das ações de mitigação de cada tipo de poluição no cômputo geral da poluição gerada na Bacia. Sem este cuidado, estar-se-á sujeitando qualquer ação de despoluição na Bacia à ineficácia. 0 modelo indicou que a poluição difusa pode ser até mais grave que a poluição pontual, o que reforça a necessidade de se investir mais em estudos para quantificar a contribuição da carga difusa.

- O modelo permite avaliar a influência da não consideração de Viamão no processo de elaboração das alternativas para reduzir a degradação ambiental na Bacia do Arroio Dilúvio.

- A construção de um modelo através de programação computacional permite explorar a criatividade do desenvolvedor, permitindo a incorporação de mais elementos do contexto decisório.

- Algo tão imprescindível quanto a caracterização do modelo é o detalhe de como esta- 
rão dispostas as informações fornecidas e processadas. Como se trata basicamente de um programa computacional, é importante que a interface gráfica seja clara o suficiente para transmitir as informações de modo que o modelo cumpra o objetivo de melhorar o entendimento das alternativas de gestão. Para isso, sugere-se que as informações do modelo estejam dispostas em tabelas, gráficos e mapas temáticos. Este último talvez seja o ponto mais marcante do modelo proposto, pois isto normalmente não é feito pelos pacotes computacionais tradicionais de simulação dinâmica, os quais geralmente fornecem modelos genéricos dirigidos a um público-alvo grande sem se preocuparem com as informações espaciais. Um mapa permite comparar a distribuição espacial dos diversos parâmetros rapidamente e com menos esforço, o que deixa mais tempo para a elaboração das alternativas. Além dos mapas, que nos ajudam a identificar as principais sub-bacias geradoras de poluição, os gráficos da propagação das concentrações dos poluentes ao longo do Dilúvio são muito importantes para avaliar como as medidas de controle nas sub-bacias repercutem ao longo do arroio.

Como principais aspectos negativos, citam-

se:

- A simples utilização de relações empíricas entre densidade habitacional e a concentração de poluentes certamente não condiz fielmente com a realidade, mas, na ausência de modelos e dados mais confiáveis e precisos, estas relações são bastante úteis para se ter um prognóstico preliminar da possível quantidade de poluentes gerada. Essas aproximações, apesar de imprecisas, fazem jus à idéia de que quanto menos saneado o ambiente, maior a contaminação do solo por estes poluentes. 0 ideal seria se pudéssemos descrever cada um dos parâmetros no mínimo detalhe, mas sabe-se que tal representação na maioria das vezes é inviável ou impraticável. Além do mais, a construção de modelos de simulação dinâmica pode ser sempre aperfeiçoada, desde que sejamos capazes de descrever com mais detalhes 0 processo.
- Calibração e validação: apesar de a idéia inicial ser a aplicação para fins de um planejamento preliminar, a falta de calibração dos processos físicos pode gerar incredulidade das pessoas que utilizam o modelo. Um passo muito importante, mas que não foi feito, é a utilização de dados reais do passado para calibrar o módulo físico do modelo.

- Algo que provavelmente gera desconfiança dos usuários em relação ao modelo de simulação construído no estudo de caso é a questão da simplificação dos processos físicos, no caso o efeito da não consideração da hidrodinâmica e da interação dos poluentes no meio. U ma recomendação importante é que se deve tomar cuidado para que as simplificações do modelo não conduzam a uma distorção da realidade, o que pode levar a uma tomada equivocada de decisão. Esta desconfiança influenciou na credibilidade de todo o modelo, principalmente perante os técnicos que conhecem mais profundamente estes aspectos. Isto pode ser corrigido com a sofisticação do modelo, o que não é a intenção deste trabalho, cujo objetivo é criar um modelo para servir de ferramenta para ajudar na compreensão do processo como um todo.

\section{AGRADECIMENTOS}

O s autores agradecem o apoio financeiro da Coordenação de Aperfeiçoamento de Pessoal de Nível Superior (CAPES) e aos funcionários dos diversos órgãos da Prefeitura de Porto Alegre envolvidos com o Programa Pró-Dilúvio por terem aceitado participar desta pesquisa realizada no Programa de Pós-Graduação em Engenharia de Recursos Hídricos e Saneamento Ambiental do Instituto de Pesquisas H idráulicas da Universidade Federal do Rio Grande do Sul.

\section{REFERÊNCIAS}

BOLLMANN, H. A. Relação da densidade populacional sobre variáveis de qualidade físico-química das águas superficiais em microbacias hidrográficas urbanas sem cobertura sanitária em Porto Alegre 
- RS. 2003. 145f. Tese (Doutorado em Engenharia) Programa de Pós-Graduação em Engenharia de Recursos Hídricos e Saneamento Ambiental, Instituto de Pesquisas Hidráulicas, Universidade Federal do Rio Grande do Sul, Porto Alegre/RS. 2003.

DE LUCA, S. J.; CASTRO, C. B.; IDE, C. N. Contaminação da chuva e da drenagem pluvial. Ambiente, São PauIo/SP, v. 4, n. 1, p. 49-54, 1990.

FAO (Food and Agriculture Organization of the United Nations). Lead Virtual Research and Development Centre. Livestock and Environment Toolbox. Disponível em: <http://lead.virtualcenter.org/pt/dec/ toolbox/index.htm>. Acesso em: 21 de mar. 2006.

IBGE (Instituto Brasileiro de Geografia e Estatística). Censo Demográfico. 2000.

MIT SDEP (System Dynamics in Education Project). System Dynamics. Disponível em: <http://sysdyn. clexchange.org/sd-intro/home.html>. Acesso em: 18 de out. 2010.

OECD (Organization for Economic Co-operation and Development). OECD Environmental Indicators: Development, Measurement and Use (Reference Paper). Paris: OECD Publications. 2003. 37p.

OECD (Organization for Economic Co-operation and Development). OECD Environmental Indicators: Towards Sustainable Development. Paris: OECD Publications. 2001. 152p.

OLIVEIRA, O. F. Modelo para negociar as alternativas de gestão de Bacias: o caso do Programa PróDilúvio em Porto Alegre, RS. 2006. 116f. Dissertação (Mestrado em Engenharia) - Programa de PósGraduação em Recursos Hídricos e Saneamento Ambiental, Instituto de Pesquisas Hidráulicas, Universidade Federal do Rio Grande do Sul, Porto Alegre/RS. 2006.

RIZZO, M. D.; MOUSER, P. J.; WHITNEY, D. H.; MARK, C. D.; MAGAREY, R. D.; VOINOV, A. A. The comparison of four dynamic systems-based software packages: Translation and sensitivity analysis. Environmental Modelling \& Software. v. 21, p. 1491-1502, 2006.

STAVE, K. A. A system dynamics model to facilitate public understanding of water management options in Las Vegas, Nevada. Journal of Environmental Management. v. 67, n. 4, p. 303-313, abr. 2003.

VON SPERLING, M. Introdução à qualidade das águas e ao tratamento de esgotos. 2. ed. Belo Horizonte: Departamento de Engenharia Sanitária e Ambiental/ Universidade Federal de Minas Gerais, 1996. 240 p. (Princípios do tratamento biológico de águas residuárias, v.1).
The Use Of Dynamic Simulation As A Tool To Support River Basin Management: The Case Of Arroio Dilúvio In Porto Alegre, RS

\section{ABSTRACT}

The use of hydrological models to understand the water cycle behavior in a river basin is a current practice in planning for the development of water resources. H owever, it has not always been easy to use these models in the decision-making process. This is mainly due to the fact that to use these models, the stakeholders must have specific kn owledge of the parameters that were modeled. Besides, the amount of elements needed to describe hydrological behavior may make it difficult to understand the system as a whole In order to overcome this difficulty, it is proposed to use dynamic simulation models based on the fundamentals of the field of study known as "systems dynamics", whose purpose it is to study complex systems considering all their constituent elements simultaneously. These models are constructed to make it easier to evaluate a complex system by means of analysis of the influence of each element that is part of it over the others and over the whole. Considering the river basin as the system to be studied, a dynamic simulation model was created to support the decision-making process in a practical case, the Pro-Dilúvio Program of the City Administration of Porto Alegre (RS), which aims at promoting actions that will lead to water quality improvement in the Arroio Dilúvio River basin, through the joint efforts of several municipal agencies. Among the difficulties encountered are the identification of the priority areas to fight pollution generated by the discharge of domestic effluents and diffuse pollution from rainwater. Among other things, it was observed that the use of dynamic simulation models allows the stakeholders to obtain more information about the problem, and applying these models in groups may be quite useful to facilitate negotiating the alternative to be adopted, thus reaching a consensus solution. Despite these positive results, it was also found that the simplifications performed during the con ception of these models may lead to mistrust among the users, or even induce mistaken decision-making.

Key-words: Basin management; dynamic simulation; consensus solutions; point and diffuse pollution. 